\title{
PERAN SWITCHING COSTS SEBAGAI VARIABEL MODERASI PADA PENGARUH KEPUASAN ATAS KUALITAS JASA TERHADAP LOYALITAS NASABAH PT. BANK NEGARA INDONESIA (PERSERO) TbK. CABANG UNAIR DI SURABAYA
}

\author{
Indrianawati Usman dan Ricky Gandhi Saputra* \\ Fakultas Ekonomi Universitas Airlangga
}

\begin{abstract}
This paper examine the influence of satisfaction at service quality (SERVQUAL) that related to cutomer loyalty with moderated by switching costs in PT. Bank Negara Indonesia (Persero) Tbk branch Unair Surabaya. Variable conduct in this paper is satisfaction at service quality $(X)$, switching costs (Z), and loyalty (Y). Sampling is conducted by purposive non random sampling and use moderated regression anaysis to analyze data. The result indicate effect of customer satisfaction on loyalty in customers is less when switching cost is perceived to be high rather than low. In other words, perceived switching cost reduces customers' sensitivity to the level of customer satisfaction.
\end{abstract}

Key words: satisfaction, switching costs, loyalty

\section{Pendahuluan}

Kondisi pertumbuhan pasar yang sangat rendah dengan tingkat persaingan sangat ketat saat ini menyebabkan perusahaan-perusahaan sulit untuk meningkatkan jumlah pelanggannya. Di sisi lain, memasuki pasar baru memerlukan biaya yang cukup besar sehingga keberadaan pelanggan yang loyal sangat dibutuhkan agar perusahaan dapat bertahan hidup, hal ini mendorong suatu perusahaan harus dapat menyusun strategi yang tepat agar tidak kehilangan para pelanggannya. Perusahaan yang kurang tanggap mengantisipasi keadaan ini akan kehilangan para pelanggannya dan pada akhirnya mengalami penurunan tingkat laba yang dapat mengancam posisi investasinya. Oleh karena itu, alternatif yang lebih baik adalah melakukan berbagai upaya untuk mempertahankan pasar yang sudah ada melalui usaha meningkatkan loyalitas pelanggan.

Bank sebagai salah satu perusahaan jasa yang bergerak dalam bidang keuangan, berfungsi sebagai perantara di antara pihak-pihak yang kelebihan dana, baik perseorangan, badan usaha, yayasan, maupun lembaga pemerintah dapat menyimpan kelebihan dananya di bank dalam bentuk rekening giro, tabungan, ataupun deposito berjangka sesuai dengan kebutuhan dan preferensinya. Sementara itu, pihak-pihak yang kekurangan dan membutuhkan dana akan mengajukan peminjaman atau kredit kepada bank. Kredit tersebut dapat berupa kredit investasi, kredit modal kerja, maupun kredit konsumsi (Suseno dan Piter, 2003:129).

Hal utama yang diperioritaskan oleh bank adalah dapat bersaing dan mempertahankan nasabahnya. Salah satu kunci untuk mencapai keberhasilan tersebut adalah memberikan kualitas jasa yang prima. Lassar et al. (2000) menyatakan bahwa kualitas jasa yang dipersepsikan oleh pelanggan akan menyebabkan kepuasan atau ketidakpuasan pelanggan, sehingga kepuasan akan timbul bila pelanggan memiliki persepsi yang baik atas kualitas jasa perusahaan. Kotler (2003:61) mendefinisikan kepuasan sebagai perasaan senang atau kecewa seorang pelanggan yang muncul setelah membandingkan antara persepsi terhadap kinerja (atau hasil) suatu produk/jasa dengan harapan-harapannya. 
Menurut Parasuraman et al. (1998) kualitas jasa dibangun atas adanya perbandingan dua faktor utama yaitu persepsi pelanggan atas jasa yang secara nyata mereka terima (perceived service) dengan jasa yang sesungguhnya diharapkan atau diinginkan (expected service). Apabila jasa yang diterima atau dirasakan sesuai dengan yang diharapkan, maka kualitas jasa dipersepsikan baik dan memuaskan. Jika jasa yang diterima melampaui harapan pelanggan, maka kualitas jasa dipersepsikan sebagai kualitas yang ideal. Sebaliknya jika jasa yang diterima lebih rendah daripada yang diharapkan, maka kualitas jasa dipersepsikan buruk. Dengan demikian baik tidaknya kualitas jasa tergantung pada kemampuan penyedia jasa dalam memenuhi harapan pelanggannya secara konsisten. Zeithaml dan Bitner (2003:93) menyatakan agar pelayanan yang diberikan berkualitas, perusahaan perlu memperhatikan lima dimensi kualitas jasa yang meliputi: keandalan (reliability), daya tanggap (responsiveness), jaminan (assurance), empati (empathy), dan bukti fisik (tangible).

Kepuasan pelanggan bukanlah tujuan akhir bagi perusahaan. Segala usaha yang dilakukan perusahaan untuk memuaskan konsumen ditujukan agar dapat menjadi loyal terhadap produk, merek atau jasa (Kandapully dan Duddy, 1999). Menciptakan loyalitas konsumen merupakan hal yang penting bagi perusahaan untuk tetap mempertahankan kelangsungan usahanya karena konsumen yang loyal merupakan dasar bagi kestabilan dan pertumbuhan pangsa pasar (Duffy 2003). Menurut Griffin (2003:5) seorang pelanggan dikatakan loyal, jika menunjukkan perilaku pembelian yang didefinisikan sebagai pembelian nonrandom yang diungkapkan dari waktu ke waktu oleh suatu unit pengambilan keputusan.

Beerli et al. (2004) menyatakan bahwa kepuasan berpengaruh positif terhadap loyalitas pelanggan. Seorang konsumen yang merasa puas terhadap jasa yang diterimanya akan membentuk loyalitas terhadap jasa tersebut. Semakin tinggi kepuasan yang dirasakan, semakin tinggi pula tingkat loyalitas pelanggan tersebut. Hal sebaliknya, pelanggan yang tidak puas akan juga memiliki tingkat loyalitas yang rendah.

Menurut Bendapudi dan Berry (1997) penyebab utama loyalitas pelanggan adalah kepuasan, tetapi kepuasan tidak selalu menjadi satu-satunya strategi dalam menciptakan loyalitas pelanggan. Jones et al. (2000) menyatakan, switching costs merupakan suatu strategi dalam menciptakan loyalitas pelanggan. Strategi semacam ini penting karena membantu perusahaan mempertahankan pelanggan pada saat terjadi fluktuasi kualitas jasa dalam jangka pendek.

Ping (1993) mendefinisikan switching costs sebagai persepsi konsumen tentang biaya-biaya yang harus dikorbankan dalam beralih dari satu penyedia jasa ke penyedia jasa lainnya. Kim et al. (2003) berpendapat bahwa switching costs tidak hanya meliputi biaya-biaya dalam konteks keuangan, tetapi juga dapat berupa waktu dan usaha serta beban psikologis. Jones et al. (2000) mengungkapkan bahwa switching costs sebagai faktor penting yang mempengaruhi keputusan pelanggan untuk tetap pada penyedia jasa. Switching costs diharapkan dapat mempersulit pelanggan atau menimbulkan pengorbanan yang besar jika hendak beralih ke penyedia jasa lain.

Hasil penelitian Aydin et al. (2005) menemukan switching costs sebagai sebuah moderasi pada pengaruh kepuasan terhadap loyalitas. Switching costs yang dirasakan tinggi oleh pelanggan akan melemahkan pengaruh kepuasan terhadap loyalitas, dibandingkan dengan switching costs yang dirasakan rendah oleh pelanggan. Dengan kata lain, switching costs mengurangi kepekaan pelanggan terhadap tingkat kepuasan. Jones et al. (2000) menyatakan, switching costs menjadi bagian penting ketika pelanggan merasakan ketidakpuasan dan mengurangi reaksi pelanggan untuk beralih ke penyedia jasa lain.

BNI Cabang Unair sebagai salah satu bank yang ada di Surabaya tak luput dari persaingan, dimana aktivitas para pesaing dapat menyebabkan kehilangan nasabah dalam jumlah yang cukup besar. Agar tetap bisa bertahan di pasar, BNI Cabang Unair di Surabaya perlu 
menyusun strategi yang tepat untuk mempertahankan para nasabahnya. Oleh karena itu, penting untuk diteliti tentang kepuasan atas kualitas jasa, switching costs dan loyalitas guna mencegah beralihnya nasabah ke bank lain.

Sesuai dengan latar belakang masalah diatas, maka dalam penelitian ini yang menjadi pokok permasalahannya adalah: "Apakah switching costs memoderasi pengaruh kepuasan atas kualitas jasa terhadap loyalitas nasabah BNI Cabang Unair di Surabaya?"

Berdasarkan uraian rumusan masalah di atas, maka tujuan penelitian ini adalah untuk mengetahui peran switching costs sebagai variabel moderasi pada pengaruh kepuasan atas kualitas jasa terhadap loyalitas nasabah BNI Cabang Unair di Surabaya.

\section{Landasan Teori dan Pengembangan Hipotesis}

\section{Kepuasan Konsumen}

Untuk memenangkan persaingan dunia usaha yang semakin kompetitif, suatu perusahaan dituntut untuk lebih memperhatikan upaya pemberian kualitas jasa yang terbaik kepada para pelanggan supaya tercapai kepuasan (Parasuraman et al., 1994). Kualitas jasa yang dipersepsikan oleh pelanggan akan menyebabkan kepuasan atau ketidakpuasan pelanggan, sehingga kepuasan akan timbul apabila pelanggan memiliki persepsi yang baik atas kualitas jasa perusahaan (Lassar et al., 2000).

Menurut Kotler (2003:61) kepuasan adalah perasaan senang atau kecewa seorang pelanggan yang muncul setelah membandingkan antara persepsi terhadap kinerja (atau hasil) suatu produk/jasa dengan harapan-harapannya. Tse dan Wilton (1998) menyatakan bahwa kepuasan atau ketidakpuasan pelanggan adalah respon pelanggan terhadap evaluasi ketidaksesuaian/diskonfirmasi yang dirasakan antara harapan sebelumnya dan kinerja aktual produk/jasa yang dirasakan setelah pemakaian. Engel et al. (1990) mengungkapkan bahwa kepuasan pelanggan merupakan evaluasi purnabeli di mana alternatif yang dipilih sekurang-kurangnya memberikan hasil (outcome) sama atau melampaui harapan pelanggan, sedangkan ketidakpuasan timbul apabila hasil yang diperoleh tidak memenuhi harapan pelanggan.

\section{Switching Costs}

Menurut Porter (1980) switching costs lebih merupakan one time costs dan bukan ongoing costs. Berdasarkan perspektif ini, Burnham et al. (2003) mendefinisikan switching costs sebagai one-time costs yang dipersepsikan atau diasosiasikan pelanggan dengan proses beralih dari penyedia jasa/produk yang satu ke penyedia jasa/produk yang lain. Ping (1993) mengungkapkan, switching costs sebagai persepsi konsumen tentang biaya-biaya yang harus dikorbankan dalam beralih dari satu penyedia jasa ke penyedia jasa lainnya. Kim et al. (2003) berpendapat bahwa switching costs tidak hanya meliputi biaya-biaya dalam konteks keuangan, tetapi juga dapat berupa waktu dan usaha serta beban psikologis. Menurut Jackson (1985) dalam Aydin et al. (2005) switching costs merupakan hukuman-hukuman dalam bentuk biaya ekonomi, psikologis dan fisik yang dirasakan pelanggan akibat ketidaksetiaan dan berperan dalam menghalangi para pelanggan beralih kepada perusahaan pesaing.

Jones et al. (2000) menyatakan bahwa switching costs sebagai faktor penting yang mempengaruhi keputusan pelanggan untuk tetap pada penyedia jasa. Switching costs diharapkan dapat mempersulit pelanggan atau menimbulkan pengorbanan yang besar jika hendak beralih ke penyedia jasa lain. Morgan dan Hunt (1994) mengungkapkan switching costs sebagai sebuah faktor yang berkonstribusi dalam mempertahankan sebuah hubungan. 
Dowling dan Staelin (1994) dalam Colgate dan Lang (2001) berpendapat bahwa switching costs juga berhubungan dengan risiko yang dipersepsikan pelanggan tentang ketidakpastian dan konsekuensi-konsekuensi yang tidak diinginkan dari pembelian sebuah produk atau jasa yang baru bila beralih ke perusahaan lain/pesaing. Hal ini dikonseptualisasikan sebagai kemungkinan dari konsekuensi-konsekuensi negatif (yaitu, bahaya, kerugian, dll). Resiko yang dirasakan mewakili ketidakpastian para pelanggan tentang kerugian atau keuntungan dalam sebuah transaksi tertentu, seperti: keuangan, kinerja, sosial, keamanan dan kenyamanan.

Sementara itu, ada tiga tipologi switching costs yang dikemukakan oleh Burnham et al. (2003) antara lain:

1. Procedural Switching Costs (Information Switching Costs). Pada prinsipnya, tipe biaya ini sebagian besar menyangkut waktu dan usaha yang dikorbankan, meliputi:

a. Biaya risiko ekonomis

Berkaitan dengan ketidakpastian berupa potensi dampak negatif karena menggunakan penyedia jasa lain yang tidak terlalu dipahami oleh konsumen.

b. Biaya evaluasi

Waktu dan usaha yang dikorbankan berkaitan dengan mengevaluasi penyedia jasa lain untuk membuat keputusan beralih.

c. Set-up costs

Waktu dan usaha yang dikorbankan berkaitan dengan proses memulai hubungan dengan penyedia jasa lain.

d. Biaya belajar

Waktu dan usaha yang dikorbankan untuk mendapatkan keterampilan atau pengetahuan baru agar dapat memanfaatkan produk atau jasa dari penyedia jasa lain secara efektif.

2. Financial Switching Costs (Contractual Switching Costs). Secara garis besar, tipe biaya ini menyangkut kehilangan sumber daya yang dapat dihitung secara finansial, meliputi:

a. Benefit loss costs

Berkaitan dengan hubungan kontraktual yang menciptakan manfaat-manfaat ekonomis untuk tetap loyal pada penyedia jasa saat ini.

b. Monetary loss costs

Onetime financial outlays yang dikeluarkan oleh pelanggan saat beralih penyedia jasa. Beralih penyedia jasa seringkali menimbulkan onetime expenditures, seperti deposit atau initiation fees bagi para pelanggan baru.

3. Relational Switching Costs. Pada prinsipnya, tipe biaya ini berkaitan dengan ketidaknyamanan psikologis atau emosional karena pemutusan hubungan dan kehilangan identitas.

a. Personal relationship loss costs

Ketidaknyamanan psikologis atau emosional berkaitan dengan pemutusan hubungan yang telah dibina dengan karyawan yang biasanya berinteraksi dengan pelanggan.

b. Brand relationship loss costs

Ketidaknyamanan psikologis atau emosional berkaitan dengan pemutusan identifikasi atas merek atau penyedia jasa saat ini.

Loyalitas Konsumen

Oliver (1996:392) mendefinisikan konsep loyalitas pelanggan sebagai komitmen yang mendalam untuk pembelian ulang atau penggunaan kembali suatu produk atau jasa terpilih secara konsisten di masa yang akan datang meskipun pengaruh situasional dan usaha pemasaran memiliki potensi untuk menyebabkan perilaku berpindah. Lovelock dan Wright (2005:133), mengungkapkan loyalitas sebagai keputusan pelanggan untuk terus berlangganan pada sebuah perusahaan tertentu dalam jangka panjang, dengan membeli dan menggunakan barang dan jasa secara berulang-ulang, dan dengan suka rela merekomendasikan produk perusahaan tersebut kepada rekan-rekannya. Menurut Griffin 
(2003:5) seorang pelanggan dikatakan loyal, jika menunjukkan perilaku pembelian yang didefinisikan sebagai pembelian nonrandom yang diungkapkan dari waktu ke waktu oleh suatu unit pengambilan keputusan.

Odin et al. (2001) menyatakan secara garis besar, loyalitas merek dan loyalitas pelanggan didominasi dua aliran utama, yakni aliran stokastik (behavioral) dan aliran deterministik (attitude). Dengan kata lain, loyalitas merek dapat ditinjau dari merek apa yang dibeli konsumen dan bagaimana perasaan atau sikap konsumen terhadap merek tertentu. Dapat dijelaskan sebagai berikut:

1. Aliran Stokastik atau Perspektif Behavioral

Berdasarkan perspektif ini, loyalitas merek diartikan sebagai pembelian ulang suatu merek secara konsisten oleh pelanggan. Setiap kali seorang pelanggan membeli ulang sebuah produk (misalnya jasa travel, reparasi, carpet cleaning dan seterusnya), bila ia membeli merek produk yang sama, maka ia dikatakan pelanggan yang setia pada merek tersebut dalam kategori produk bersangkutan.

2. Aliran Deterministik atau Perspektif Attitude

Dalam kategori ini, loyalitas pelanggan dipandang sebagai komitmen psikologis pelanggan dalam pembelian, tanpa perlu mempertimbangkan secara spesifik perilaku pembelian efektif.

Dick dan Basu (1994) berusaha mengintegrasikan perspektif sikap dan perilaku ke dalam satu model komprehensif. Dengan mengkombinasikan komponen sikap dan perilaku pembelian ulang, maka didapatkan empat jenis loyalitas. Dapat dilihat pada gambar berikut ini:

\begin{tabular}{|c|c|c|c|}
\hline & \multicolumn{2}{|c|}{ Empat Jenis Loyalitas } \\
\hline & & \multicolumn{2}{|c|}{ Repeat Patronage } \\
\hline & & High & Low \\
\hline & High & Loyalty & Latent Loyalty \\
\hline Relative Atitude & Low & Spurious Loyalty & No Loyalty \\
\hline
\end{tabular}

Sumber: Dick, A and Basu, K. 1994. Customer Loyalty: Toward an Integrated Conceptual Framework. Journal of Marketing Science, Vol. 22, pp. 99-113

Dari gambar diatas dapat dijelaskan bahwa ada empat jenis loyalitas pelanggan, yaitu:

1. Tanpa Loyalitas (no loyalty)

Pelanggan yang frekuensi pembelian ulangnya rendah dan sikapnya juga rendah. Sikap yang rendah ini menunjukkan bahwa perusahaan kurang berhasil dalam mengkombinasikan produk atau karena dalam pasar merek-merek yang ada dianggap tidak memiliki perbedaan oleh pelanggan.

2. Loyalitas Palsu (spurious loyalty)

Pelanggan yang berulang kali melakukan pembelian tetapi sikap terhadap merek relatif rendah. Hal ini terjadi karena faktor situasional atau karena kondisi pasar yang memaksa pelanggan untuk melakukan pembelian ulang.

3. Loyalitas Tersembunyi (latent loyalty)

Pelanggan seperti ini banyak terjadi karena pengaruh dari lingkungan pasar dimana norma-norma dan situasi sosial kurang mendukung pelanggan untuk melakukan pembelian ulang.

4. Loyalitas (loyalty) 
Situasi ini merupakan situasi ideal yang paling diharapkan para pemasar, di mana pelanggan bersikap positif terhadap jasa atau penyedia jasa bersangkutan dan disertai pola pembelian ulang yang konsisten.

Pengaruh Kepuasan Terhadap Loyalitas Dimoderasi oleh Switching Costs

Pada dasarnya tujuan dari suatu bisnis adalah untuk menciptakan para pelanggan yang puas. Terciptanya kepuasan pelanggan memberikan manfaat, hubungan antara perusahaan dengan pelanggannya menjadi harmonis, memberi dasar yang baik bagi pembelian ulang dan terciptanya loyalitas pelanggan (Schnaars 1991:312).

Pelanggan yang merasa puas, kurang merasakan manfaat dari berpindah ke penyedia jasa lain sehingga ada keinginan yang lebih tinggi untuk tetap loyal kepada penyedia jasa saat ini. Hal sebaliknya dapat terjadi apabila pelanggan merasa tidak puas dengan jasa yang diterimanya (Anderson dan Sullivan, 1993). Kepuasan pelanggan atau kesenangan akan menciptakan ikatan emosional terhadap perusahaan yang hasilnya adalah loyalitas pelanggan yang tinggi (Lassar et al. 2000).

Fornel et al. (1996) mengungkapkan bahwa kepuasan merupakan kunci dari loyalitas pelanggan. Hal ini menunjukkan bahwa terdapat pengaruh antara kepuasan dengan loyalitas pelanggan. Beerli et al. (2004) menyatakan bahwa kepuasan berpengaruh positif terhadap loyalitas pelanggan. Seorang konsumen yang merasa puas terhadap jasa yang diterimanya akan membentuk loyalitas terhadap jasa tersebut. Semakin tinggi kepuasan yang dirasakan, semakin tinggi pula tingkat loyalitas pelanggan tersebut. Hal sebaliknya, pelanggan yang tidak puas akan juga memiliki tingkat loyalitas yang rendah.

Menurut Bendapudi dan Berry (1997) penyebab utama loyalitas pelanggan adalah kepuasan, tetapi kepuasan tidak selalu menjadi satu-satunya strategi dalam menciptakan loyalitas pelanggan. Jones et al. (2000) menyatakan, switching costs merupakan suatu strategi dalam menciptakan loyalitas pelanggan. Strategi semacam ini penting karena membantu perusahaan mempertahankan pelanggan pada saat terjadi fluktuasi kualitas jasa dalam jangka pendek.

Hasil penelitian Aydin et al. (2005) menemukan switching costs sebagai sebuah moderasi pada pengaruh kepuasan terhadap loyalitas. Switching costs yang dirasakan tinggi oleh pelanggan akan melemahkan pengaruh kepuasan terhadap loyalitas, dibandingkan dengan switching costs yang dirasakan rendah oleh pelanggan. Dengan kata lain, switching costs mengurangi kepekaan pelanggan terhadap tingkat kepuasan.

Hal yang senada dinyatakan oleh Jones et al. (2000) pengaruh kepuasan terhadap loyalitas menjadi menurun pada saat pelanggan merasakan tingkat switching costs yang tinggi (dan juga apabila pada saat kepuasan meningkat, pengaruh switching costs terhadap loyalitas menjadi menurun). Switching costs menjadi bagian penting ketika pelanggan merasakan ketidakpuasan dan mengurangi reaksi pelanggan untuk beralih ke penyedia jasa lain.

Jackson (1985) dalam Yang dan Peterson (2004) menyatakan, pelanggan yang tidak puas dapat menjadi loyal kepada penyedia jasa saat ini ketika merasakan switching costs yang tinggi. Balabanis et al. (2004) berpendapat, hal sebaliknya dapat terjadi apabila pelanggan merasakan switching costs yang rendah, ketidakpuasan mengakibatkan pelanggan akan beralih ke penyedia jasa lain.

Soderlund (2003) mengungkapkan bahwa pada saat pelanggan merasa puas atas jasa yang diterima, pelanggan kurang merasakan peran dari switching costs dalam menciptakan loyalitas. Hal serupa dinyatakan oleh Ranaweera dan Prabhu (2003) bahwa switching costs tidak berperan dalam menciptakan loyalitas pada saat pelanggan merasa puas. 
Hipotesis dan Model Analisis

Berdasarkan rumusan masalah dan tujuan penelitian yang telah dikemukakan, maka hipotesis yang diajukan adalah sebagai berikut: "Switching costs secara signifikan memoderasi pengaruh kepuasan atas kualitas jasa terhadap loyalitas nasabah BNI Cabang Unair di Surabaya."

Untuk mempermudah pemahaman dan maksud dilakukannya penelitian ini, maka dirancang suatu model analisis sebagaimana dapat dilihat pada gambar berikut:

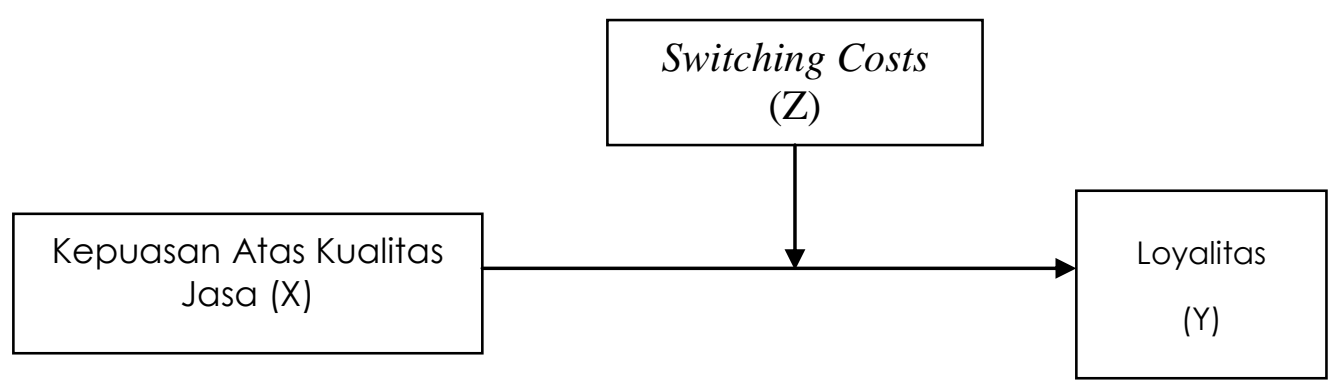

\section{Metode Penelitian}

Populasi dan Sampel

Populasi dalam penelitian ini adalah para nasabah BNI Cabang Unair di Surabaya, yang berusia 18 tahun keatas. Batasan ini ditentukan dengan pertimbangan, nasabah yang telah berusia 18 tahun ke atas lebih dianggap telah dapat mengambil keputusan memilih suatu bank tertentu melalui proses keputusan yang rasional.

Populasi tersebut akan ditarik sampel dengan menggunakan teknik Purposive Non Random Sampling. Menurut Indriantoro dan Supomo (1999:130) yang dimaksud Non Random Sampling adalah suatu sampling dimana tidak semua individu di dalam populasi diberi peluang yang sama untuk menjadi anggota sampel. Sedangkan Purposive Sampling adalah pemilihan sekelompok subyek berdasarkan atas ciri-ciri atau sifat-sifat tertentu yang dipandang mempunyai hubungan yang erat dengan ciri-ciri atau sifat-sifat populasi yang sudah diketahui sebelumnya. Sebutan Purposive menunjukkan bahwa teknik ini digunakan untuk mencapai tujuan tertentu.

Berdasarkan pasal 40 ayat 1 Undang-Undang Perbankan No.7 tahun 1992 yang menyatakan data mengenai jumlah nasabah adalah merupakan rahasia bank. Sehingga, dalam penelitian ini ukuran sampel ditentukan berdasarkan pendapat Sudman (1975) dalam Aaker et al. (1995:393) yang menyarankan bahwa jumlah sampel seharusnya cukup besar sehingga bila dibagi dalam grup-grup, masing-masing grup akan akan mempunyai ukuran sampel minimal 100 atau lebih, karena dalam penelitian ini tidak ada pembagian grup, maka sampel penelitian dianggap merupakan satu grup. Dengan demikian, jumlah sampel yang digunakan dalam penelitian ini adalah 100 responden nasabah BNI Cabang Unair di Surabaya.

\section{Teknik Analisis}

Dalam penelitian ini, teknik analisis yang digunakan adalah Moderated Regression Analysis (MRA), merupakan aplikasi khusus dari Regresi Linier Berganda dimana dalam persamaan regresinya mengandung unsur interaksi (perkalian dua variabel independen). Variabel perkalian antara $X$ dengan $Z$ merupakan variabel moderasi oleh karena menggambarkan 
moderasi variabel Z pada pengaruh X terhadap Y. Ghozali (2001:153) menyatakan bahwa uji efek moderasi dapat dilakukan dengan melihat signifikansi uji † untuk interaksi (X.Z). Sedangkan arah moderasinya dilihat dari koefisien regresi interaksi (X.Z), jika bernilai negatif maka efek moderasi akan memperlemah pengaruh variabel independen terhadap variabel dependen, dan sebaliknya.

\section{Analisis dan Pembahasan}

Hasil yang diperoleh dari perhitungan terhadap tanggapan konsumen terhadap variabelvariabel bebas, moderasi dan terikat dalam penelitian ini dapat di lihat pada tabel berikut:

Hasil Moderated Regression Analysis

\begin{tabular}{|c|c|c|c|c|c|c|}
\hline No. & \multicolumn{3}{|c|}{ Variabel } & $\begin{array}{c}\text { Koefisien } \\
\text { Regresi }\end{array}$ & t-hitung & $\begin{array}{c}\text { Tingkat Sign. } \\
\text { (\%) }\end{array}$ \\
\hline 1. & \multicolumn{3}{|c|}{ Kepuasan Atas Kualitas Jasa (X) } & 1,412 & 13,567 & 0,000 \\
\hline 2. & \multicolumn{3}{|c|}{ Switching Costs (Z) } & 0,203 & 2,793 & 0,006 \\
\hline 3. & \multicolumn{3}{|c|}{ Interaksi (X.Z) } & $-0,663$ & $-4,270$ & 0,000 \\
\hline 4. & \multicolumn{3}{|c|}{ Konstanta (a) } & 4,104 & & \\
\hline $\mathrm{R}$ & $=0,827$ & $F_{\text {hitung }}$ & $=69,328$ & & & \\
\hline $\mathrm{R}^{2}$ & $=0,684$ & Sign. & $=0,000$ & & & \\
\hline
\end{tabular}

Sumber: data diolah

Berdasarkan hasil analisis pada tabel diatas maka persamaan regresi yang dihasilkan adalah:

$$
Y=4,104+1,412 X+0,203 Z-0,663 X . Z+e
$$

Pengaruh antara kepuasan atas kualitas jasa terhadap loyalitas nasabah ditunjukkan oleh koefisien regresi variabel kepuasan atas kualitas jasa (X) yang positif, artinya apabila kepuasan atas kualitas jasa meningkat maka loyalitas nasabah juga meningkat. Koefisien regresi interaksi kepuasan atas kualitas jasa dengan switching costs (X.Z) menunjukkan nilai yang negatif, artinya apabila switching costs meningkat maka pengaruh kepuasan atas kualitas jasa terhadap loyalitas nasabah akan menjadi lemah atau menurun.

Analisis uji t dilakukan dengan membandingkan nilai thitung dengan nilai tabel. Adapun hasil uji † untuk interaksi kepuasan atas kualitas jasa dengan switching costs (X.Z), thitung < tabel (thitungX.Z $=-4,270$. ttabel $=-1,660$ ). Hasil uji $\dagger$ ini menunjukkan bahwa switching costs memoderasi pengaruh kepuasan atas kualitas jasa terhadap loyalitas nasabah. Hal ini juga didukung dari tingkat signifikansi uji † untuk interaksi kepuasan atas kualitas jasa dengan switching costs (X.Z) yang berada di bawah 0,05.

Nilai $R^{2}$ model sebesar 0,684 menunjukkan bahwa 68,4\% perubahan loyalitas nasabah dapat dijelaskan oleh kepuasan atas kualitas jasa (X), switching costs (Z) dan interaksi (X.Z). Sedangkan sisanya sebesar $31,6 \%$ dapat dijelaskan oleh variabel-variabel lain yang tidak termasuk dalam model.

\section{Pembahasan}

Berdasarkan Moderated Regression Analysis diperoleh koefisien regresi interaksi kepuasan atas kualitas jasa dengan switching costs (X.Z) menunjukkan nilai yang negatif, artinya 
apabila switching costs meningkat maka pengaruh kepuasan atas kualitas jasa terhadap loyalitas nasabah akan menjadi lemah atau menurun. Hasil signifikansi uji † untuk interaksi kepuasan atas kualitas jasa dengan switching costs (X.Z) sebesar 0,000. Nilai probabilitas ini kemudian dibandingkan dengan level of significant sebesar 0,05. Dikarenakan nilai probabilitas lebih kecil dari 0,05 maka hal ini menunjukkan bahwa switching costs memoderasi pengaruh kepuasan atas kualitas jasa terhadap loyalitas nasabah BNI Cabang Unair di Surabaya. Switching costs yang dirasakan tinggi akan mempertahankan nasabah yang tidak puas untuk tetap loyal pada BNI Cabang Unair di Surabaya. Switching costs yang dirasakan nasabah berkaitan dengan waktu dan usaha (procedural switching costs), kehilangan sumber daya secara finansial (financial switching costs), dan ketidaknyamanan psikologis atau emosional (relational switching costs) yang harus dikorbankan apabila nasabah beralih ke bank lain. Selanjutnya, pada saat nasabah merasa puas atas jasa yang diterima, switching costs tidak berperan dalam menciptakan loyalitas. Nasabah yang puas, kurang merasakan manfaat dari berpindah ke bank lain dan memiliki keinginan yang lebih tinggi untuk tetap loyal kepada BNI Cabang Unair di Surabaya, sehingga nasabah tidak merasakan biaya-biaya (waktu dan usaha, vang, serta ketidaknyamanan psikologis atau emosional) yang dikorbankan untuk beralih ke bank lain.

Hasil penelitian ini mendukung penelitian yang dilakukan oleh Aydin et al. (2005), yang menyatakan bahwa switching costs sebagai sebuah moderasi pada pengaruh kepuasan terhadap loyalitas. Switching costs yang dirasakan tinggi oleh pelanggan akan melemahkan pengaruh kepuasan terhadap loyalitas, dibandingkan dengan switching costs yang dirasakan rendah oleh pelanggan. Dengan kata lain, switching costs mengurangi kepekaan pelanggan terhadap tingkat kepuasan.

\section{Simpulan dan Saran}

Berdasarkan analisis dan perhitungan-perhitungan statistik dapat ditarik simpulan sebagai berikut:

1. Hipotesis dalam penelitian ini terbukti bahwa switching costs memoderasi secara signifikan pengaruh kepuasan atas kualitas jasa terhadap loyalitas nasabah BNI Cabang Unair di Surabaya. Hasil penelitian ini diperoleh nilai $R^{2}$ sebesar 0,684 menunjukkan bahwa $68,4 \%$ perubahan loyalitas nasabah dapat dijelaskan oleh kepuasan atas kualitas jasa (X), switching costs (Z) dan interaksi (X.Z). Sedangkan sisanya sebesar $31,6 \%$ dapat dijelaskan oleh variabel-variabel lain yang tidak termasuk dalam model.

2. Koefisien regresi interaksi kepuasan atas kualitas jasa dengan switching costs (X.Z) menunjukkan nilai yang negatif, artinya apabila switching costs meningkat maka pengaruh kepuasan atas kualitas jasa terhadap loyalitas nasabah akan menjadi lemah/menurun.

Berdasarkan pada hasil diatas, maka dapat disarankan beberapa hal berikut:

1. Switching costs sebagai variabel moderasi, memperlemah pengaruh kepuasan atas kualitas jasa terhadap loyalitas nasabah. Ini adalah temuan penting bagi manajemen BNI Cabang Unair di Surabaya, artinya bahwa loyalitas nasabah tidak hanya muncul pada saat nasabah merasakan kepuasan. Bahkan pada saat nasabah tidak puas, switching costs yang dirasakan tinggi akan mempertahankan nasabah untuk tetap loyal pada BNI Cabang Unair di Surabaya.

2. BNI Cabang Unair di Surabaya diharapkan dapat menciptakan switching costs untuk mempersulit nasabah atau menimbulkan pengorbanan yang besar jika nasabah hendak beralih ke bank lain. Adapun hal-hal yang dapat dilakukan oleh pihak BNI Cabang Unair di Surabaya untuk menciptakan switching costs antara lain:

a. Membangun atau membina hubungan yang akrab dengan nasabah. Familiaritas nasabah dengan karyawan dapat menciptakan ikatan sosial dan perasaan nyaman, yang tidak bisa langsung didapatkan dari bank yang baru. Apabila beralih ke bank lain, nasabah akan merasakan ketidaknyamanan secara psikologis karena memutuskan hubungan yang sudah terjalin. 
b. Menciptakan manfaat-manfaat ekonomis bagi nasabah, namun bila nasabah beralih ke bank lain, manfaat-manfaat tersebut secara otomatis akan hilang. Seperti, memberikan poin-poin undian berhadiah kepada nasabah bila melakukan menabung dalam kelipatan nominal tertentu, atau memberikan diskon bagi nasabah jika berbelanja/bertransaksi menggunakan kartu debit maupun kredit.

c. Meningkatkan biaya menutup rekening, sehingga bila nasabah ingin beralih ke bank lain membutuhkan lebih banyak dana yang harus dikorbankan.

3. Penelitian selanjutnya dapat menguji model penelitian ini pada subyek bidang yang berbeda dan mempertimbangkan jenis variabel bebas yang lain.

\section{Daftar Referensi}

Aaker, David A., V. Kumar and George S. Day. 1995. Marketing Research, Sixth Edition. John Wiley and Sons. Inc.

Anderson, E.W. and Sullivan, M. 1993. The Antecedents and Consequences of Consumer Satisfaction for Firms, Marketing Science, Vol.12, Spring, pp: 125-43.

Aydin, Serkan., Gokhan Ozer and Omer Arasil. 2005. Customer Loyalty and The Effect of Switching Costs as a Moderator Variable: A Case in The Turkish Mobile Phone Market, Journal of Marketing, Vol. 23, pp: 89-103.

Balabanis, George., Nina Reynold., and A. Simintiras. 2004. Bases of E-Store Loyalty: The Interaction Between Perceived Switching Costs and Satisfaction, Journal of Marketing, Vol. 15.

Beerli, Asuncion., Josefa D. Martin and Agustin Quintana. 2004. A Model of Customer Loyalty in The Retail Banking Market, Journal of Marketing, Vol. 38, pp: 253-275.

Bendapudi, Neeli and Leonard L. Berry. 1997. Customers' Motivations for Maintaining Relationships with Service Providers, Journal of Retailing, Vol. 73, pp: 15-37.

Burnham, T.A., J.K. Frels and V. Mahajan. 2003. Consumer Switching Costs: A Typology, Antecedents and Concequences, Journal of the Academy of Marketing Science, Vol. 31, No.2, pp: 109-126.

Colgate, Mark and Bodo Lang. 2001. Switching Costs in Consumer markets: an Investigation of The Financial Services Industry, Journal of Consumer Marketing, Vol. 18, pp: 332347.

Dick, A.S. and K. Basu. 1994. Customer Loyalty: Toward and Integrated Conceptual Framework, Journal of the Academy of Marketing Sience, Vo. 22, pp. 99-113.

Duffy, Dennis L., 2003. Internal and External Factors Which Affect Customer Loyalty, Journal of Consumer Marketing, Vol. 20, pp: 480-485.

Engel, James F., Roger DB., Paul WM. 1990. Consumer Behavior. 6th edition. Chicago: The Dryden Press.

-----. Johnson, M.D., Anderson, E.W., Cha, J., Bryant, B.E. 1996. The American Customer Index Nature, Purpose, and Findings, Journal of Marketing, Vol. 60., No. October, pp: 7-18.

Ghozali, Imam. 2001. Aplikasi Analisis Multivariate Dengan Program SPSS. Semarang: Badan Peneliti Universitas Diponegoro.

Griffin, Jill. 2003. Customer Loyalty: Menumbuhkan dan Mempertahankan Kesetiaan Pelanggan. Edisi Revisi. Terjemahan. Jakarta: Penerbit Erlangga.

Indriantoro, Nur dan Bambang Supomo. 1999. Metode Penelitian Bisnis Untuk Akuntansi dan Manajemen. Edisi I. Yogjakarta.

Jones, Michael A., David L. Mothersbaugh and Sharon E. Beatty. 2000. Why Customer Stay: Measuring The Underlying Dimensions of Services Switching Costs and Managing Their Differential Strategic Outcomes, Journal of Business Research, Vol.55, pp: 441-450.

Kandampully, Jay and Ria Duddy. 1999. Relationship Marketing: A Concept Beyond the Primary Relationship, Marketing Intelligence and Planning, Vol. 17, pp: 315-323

Kim, M., Kliger, D., Vale, B. 2003, "Estimating Switching Costs: The Case of Banking", Journal of Financial Intermediation, Vol. 12 No.1, pp.25-56. 
Kotler, Philip. 2003. Marketing Management, Eleventh Edition, New Jersey: Prentice-Hall International, Inc.

Lassar, Walfried M., Chris Manolis and Robert D. Winsor. 2000. Service Quality Perspectives and Satisfaction in Private Banking, Journal of Services Marketing, Vol. 14, pp: 244-271.

Lovelock, Christopher H. dan Lauren K. Wright. 2005. Manajemen Pemasaran Jasa. Terjemahan. Jakarta: Indeks.

Morgan, R.M., Hunt, S.D. 1994. The Commitment-Trust Theory of Relationship Marketing", Journal of Marketing, Vol. 58 No.3, pp.20-38.

Odin, Y., N. Odin and P. Vallette-Florence. 2001. Conceptual and Operational Aspects of Brand Loyalty: An Empirical Investigation, Journal of Business Research, Vol. 53, pp. 7584.

Oliver, Richard L. 1996. Satisfaction: A Behavioral Perspective on The Consumer, International Edition, Singapore: McGraw Hill.

Oliver, Richard L. 1994. Reassessment of Expectations as a Comparison Standard in Measuring Service Quality: Implications for Future Research, Journal of Marketing, Vol. 58, January, pp.111-124.

Oliver, Richard L.1998. SERVQUAL: A Multiple-ltem Scale For Measuring Consumer Perceptions of Service Quality, Journal of Retailing, Vol. 64, No. 1.

Ping, R.A. 1993. The Effects of Satisfaction and Structural Constraints on Retailer Exiting, Voice, Loyalty, Opportunism, and Neglect, Journal of Retailing, Vol. 69 No.3, pp: 320-52.

Porter, Michael E. 1980. Competitive Strategy. New York: Free Press.

Ranaweera, Chatura and Jaideep Prabhu. 2003. The Influence of Satisfaction and Switching Barriers on Customer Retention in a Continuous Purchasing Setting, International Journal of Service Industry Management, Vol. 14, No.14, pp: 374-395.

Schnaars, Steven. 1991. Marketing Strategy: A Customer Driven Approach. New York: The Free Press, Mac Milan Inc.

Soderlund, Claes Robert Julander Magnus. 2003. Effects of Switching Costs on Satisfaction, Repurchase intentions and Loyalty, Journal of Marketing, January. No.1.

Suseno dan Piter Abdullah. 2003. Bank Indonesia Bank Sentral Republik Indonesia. Jakarta: Pusat Pendidikan dan Studi Kebanksentralan.

Tse, D.K., and P.C. Wilton. 1998. Models of Consumer Satisfaction Formation: An Extension, Journal of Marketing Research, pp: 204-212.

Yang, Zhilin dan Robin T. Peterson. 2004. Customer Perceived Value, Satisfaction, and Loyalty: The Role of Switching Costs, Journal of Marketing, Vol. 21, pp: 799-822.

Yang and Mary Jo Bitner. 2003. Service Marketing: Integrating Customer Focus Across The Firm, International Edition, New York: McGraw Hill.

*Indrianawati Usman dan Ricky Gandhi Saputra staf Pengajar dan alumnus Fakultas Ekonomi Universitas Airlangga. Komentar dan saran yang membangun bisa melalui email indrianawati@yahoo.com 